\title{
Powder for Concentrate for Dispersion for Infusion Dosage Form
}

National Cancer Institute

\section{Source}

National Cancer Institute. Powder for Concentrate for Dispersion for Infusion Dosage

Form. NCl Thesaurus. Code C149810.

Solid sterile preparation consisting of one or more powders intended to be dispersed in the specified liquid to obtain a concentrate for dispersion for infusion, which must subsequently be diluted before administration as a dispersion for infusion. 